\section{Commentary: Basilar segmentectomy: A new weapon against cancer for the modern thoracic surgeon?}

\author{
Juan A. Muñoz-Largacha, MD, ${ }^{\mathrm{a}}$ and \\ Benjamin Wei, MD
}

It is well recognized that the detection of small, subcentimeter lung nodules and ground-glass opacities suspicious for malignancy has increased in the last decade, partly because of the widespread implementation of lung cancer screening in high-risk populations. As a consequence, the demand for surgical resection of these smaller lesions has also increased. ${ }^{1}$ Lobectomy continues to be the standard of care for the treatment of early-stage lung cancer. However, anatomic segmentectomy has shown comparable outcomes in a selected group of patients with specific preoperative diagnostic characteristics and functional status. ${ }^{2}$ Ongoing prospective randomized studies will help answer whether these 2 approaches are comparable for the treatment of early-stage disease. ${ }^{3,4}$

Previous reports have shown that thoracoscopic segmentectomies represent a more complex operation when compared with lobectomies. This is due to the difficult visualization of the intersegmental planes in addition to the anatomic variation of the main segmental structures and their deepness, especially within the basilar segments. ${ }^{5}$ In their article, Liu and colleagues ${ }^{6}$ describe a novel, singledirection technique for thoracoscopic basal segmentectomy with good feasibility and safety results. This article helps demystify what is an unfamiliar operation for many, if not most, thoracic surgeons, especially in the Western Hemisphere. The investigators' description of how to locate

\footnotetext{
From the ${ }^{\mathrm{a} D e p a r t m e n t}$ of Surgery, General Surgery Residency Program, and ${ }^{\mathrm{b}}$ Division of Cardiothoracic Surgery, Department of Surgery, University of Alabama at Birmingham, Birmingham, Ala.

Disclosures: Authors have nothing to disclose with regard to commercial support.

Received for publication Feb 5, 2020; accepted for publication Feb 6, 2020; available ahead of print Feb 14, 2020.

Address for reprints: Benjamin Wei, MD, Division of Cardiothoracic Surgery, Department of Surgery, University of Alabama at Birmingham, 703 19th St South,

Zeigler Research Building, Room 701, Birmingham, AL 35294 (E-mail: bwei@ uab.edu).

J Thorac Cardiovasc Surg 2020;160:1595-6

0022-5223/\$0.00

Published by Elsevier Inc. on behalf of The American Association for Thoracic Surgery

https://doi.org/10.1016/j.jtcvs.2020.02.007
}

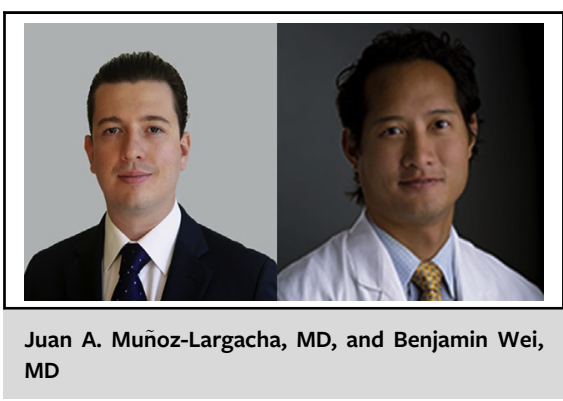

CENTRAL MESSAGE

Liu and colleagues describe a novel, single-direction technique for thoracoscopic basal segmentectomy showing the feasibility and safety of the procedure for this challenging anatomic resection.

the relevant basilar segmental structures on computed tomography scan and during thoracoscopy is especially helpful. For the patients in this study, Liu and colleagues 6 generally started the dissection by retracting the lower lobe cranially and then dissecting the inferior pulmonary vein. In $75 \%$ of patients, this was possible, whereas they started the dissection in the fissure in the other $25 \%$ of patients. The target segment is retracted, and the appropriate segmental vein is identified as the one exhibiting the most tension and then divided. Next, the bronchus is dissected distally until the segmental bronchus is identified and divided; this reveals the segmental artery that runs parallel to the segmental bronchus, which is then divided. The intersegmental plane is then demarcated with the inflation-deflation technique. If there is no crossventilation, the plane becomes obvious as the target segment remains deflated. If cross-ventilation does cause inflation of the target segment, the fact that the airway has been divided prevents rapid egress of air, leaving the relevant segment relatively inflated. Division of this plane is performed with the stapler. A total of 137 basal segmentectomies were performed, 90 single and 47 combined (ie, S9+10), with no reported perioperative mortality. Impressively, the rate of prolonged air leak (defined as air leak $>5$ days) was minimal, at 5.1\%, and 6 of 7 of these patients had undergone combined segmentectomy. The operative time for these complex procedures was reasonable, at a median of 125 minutes. More important, in all cases the final pathologic examination revealed complete 
resection with negative specimen margins. Furthermore, a considerable number of resections were performed for the more challenging segments (S9 and S10) without the need for conversion to lobectomy or open thoracotomy.

These results demonstrate the feasibility of the singledirection thoracoscopic basal segmentectomy with an excellent safety profile. That said, we should be reluctant to perform a basilar segmentectomy instead of lower lobectomy in patients with lung cancer with sufficient preoperative lung function if it means they will be more likely to develop locoregional recurrence or die of their disease. Identifying which patients truly benefit from basilar segmentectomy over lower lobectomy is a question not addressed by this study. Nonetheless, we believe this article by Liu and colleagues ${ }^{6}$ provides novel information and describes a useful surgical technique that will become more relevant as we are increasingly called to address smaller and potentially less aggressive cancers. We acknowledge the authors for the excellent visual contents in the article, which are essential for the understanding of their technique.

\section{References}

1. Nomori H, Mori T, Shiraishi A, Fujino K, Sato Y, Ito T, et al. Long-term prognosis after segmentectomy for c T1 N0 M0 non-small cell lung cancer. Ann Thorac Surg. 2019;107:1500-6.

2. Hennon M, Landreneau RJ. Role of segmentectomy in treatment of early-stage non-small cell lung cancer. Ann Surg Oncol. 2018;25:59-63.

3. Nakamura K, Saji H, Nakajima R, Okada M, Asamura H, Shibata T, et al. A phase III randomized trial of lobectomy versus limited resection for small-sized peripheral non-small cell lung cancer (JCOG0802/WJOG4607L). Jpn J Clin Oncol. 2010;40:271-4.

4. Altorki NK, Wang X, Wigle D, Gu L, Darling G, Ashrafi AS, et al. Perioperative mortality and morbidity after sublobar versus lobar resection for early-stage non-small-cell lung cancer: post-hoc analysis of an international, randomised, phase 3 trial (CALGB/Alliance 140503). Lancet Respir Med. 2018;6:915-24.

5. Oizumi H, Kanauchi N, Kato H, Endoh M, Suzuki J, Fukaya K, et al. Anatomic thoracoscopic pulmonary segmentectomy under 3-dimensional multidetector computed tomography simulation: a report of 52 consecutive cases. J Thorac Cardiovasc Surg. 2011;141:678-82.

6. Liu C, Liao H, Guo C, Pu Q, Mei J, Liu L. Single-direction thoracoscopic basal segmentectomy. J Thorac Cardiovasc Surg. 2020;160:1586-94.
See Article page 1586

\section{Commentary: Single-direction or multidirection basilar segmentectomy: Is there an easier way?}

\author{
Nazgol Seyednejad, MD, and Sebastien Gilbert, MD
}

With lung cancer screening and the seemingly everincreasing number of diagnostic chest computed tomographic scans being performed, we should expect to detect more and more early-stage lung cancers. Although still the subject of debate, it is conceivable to expect that sublobar resection could achieve results equivalent to lobectomy in selected cases. In patients with

\footnotetext{
From the Division of Thoracic Surgery, University of Ottawa, Ottawa, Ontario, Canada.

Disclosures: Authors have nothing to disclose with regard to commercial support.

Received for publication Feb 8, 2020; revisions received Feb 8, 2020; accepted for publication Feb 11, 2020; available ahead of print Feb 19, 2020

Address for reprints: Sebastien Gilbert, MD, Division of Thoracic Surgery, The Ottawa Hospital, General Campus Suite 6363, 501 Smyth Rd, Ottawa, Ontario K1H 8L6, Canada (E-mail: sgilbert@toh.on.ca).

J Thorac Cardiovasc Surg 2020;160:1596-7

$0022-5223 / \$ 36.00$

Copyright (c) 2020 by The American Association for Thoracic Surgery

https://doi.org/10.1016/j.jtcvs.2020.02.038
}

Check for updates

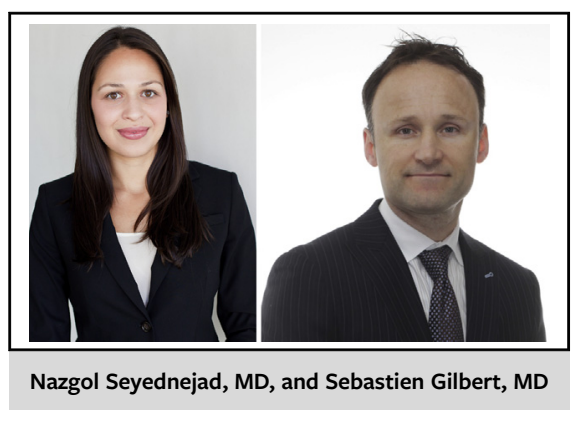

CENTRAL MESSAGE

Standardization of techniques

for complex anatomic sublobar

resections is required to facilitate

adoption by practicing surgeons

and education of trainees.

compromised pulmonary function, sublobar resection may be the only surgical option. Long-term results of large, prospective trials of lobar and sublobar resection are forthcoming (CALGB 140503, JCOG/WJOG 0802). From an oncologic standpoint, segmentectomy is more attractive than wedge resection, because it facilitates 